\title{
Effect of nitrogen dioxide and other combustion products on asthmatic subjects in a home-like environment
}

\author{
C.M. Salome*, N.J. Brown**, G.B. Marks**, A.J. Woolcock**, G.M. Johnson+, \\ P.C. Nancarrow ${ }^{+}$, S. Quigley ${ }^{+}$, J. Tiong ${ }^{++}$
}

Effect of nitrogen dioxide and other combustion products on asthmatic subjects in a home-like environment. C.M. Salome, N.J. Brown, G.B. Marks, A.J. Woolcock, G.M. Johnson, P.C. Nancarrow, S. Quigley, J. Tiong. C CERS Journals Ltd 1996.

ABSTRACT: Nitrogen dioxide $\left(\mathrm{NO}_{2}\right)$ is one of a number of nitrogen compounds that are by-products of combustion and occur in domestic environments following the use of gas or other fuels for heating and cooking. In this study, we examined the effect of two levels of $\mathrm{NO}_{2}$ on symptoms, lung function and airway hyperresponsiveness (AHR) in asthmatic adults and children. In addition, in the same subjects, we examined the effects of the same levels of $\mathrm{NO}_{2}$ mixed with combustion by-products from a gas space heater.

The subjects were nine adults, aged 19-65 yrs, and 11 children, aged 7-15 yrs, with diagnosed asthma which was severe enough to require daily medication. All subjects had demonstrable AHR to histamine. Exposures were for $1 \mathrm{~h}$ on five separate occasions, 1 week apart, to: 1) ambient air, drawn from outside the building; 2) 0.3 parts per million (ppm) $\mathrm{NO}_{2}$ in ambient air; 3) $0.6 \mathrm{ppm} \mathrm{NO}_{2}$ in ambient air; 4) ambient air + combustion by-products $+\mathrm{NO}_{2}$ to give a total of $0.3 \mathrm{ppm}$; and 5) ambient air + combustion by-products $+\mathrm{NO}_{2}$ to give a total of $0.6 \mathrm{ppm}$. Effects were measured as changes in lung function and symptoms during and $1 \mathrm{~h}$ after exposure, in AHR $1 \mathrm{~h}$ and 1 week after exposure, and in lung function and symptoms during the week following exposure.

Exposure to $\mathrm{NO}_{2}$ either in ambient air or mixed with combustion by-products from a gas heater, had no significant effect on symptoms or lung function in adults or in children. There was a small, but statistically significant, increase in AHR after exposure to $0.6 \mathrm{ppm} \mathrm{NO}_{2}$ in ambient air. However, there was no effect of $0.6 \mathrm{ppm}$ $\mathrm{NO}_{2}$ on AHR when the combustion by-products were included in the test atmosphere nor of $0.3 \mathrm{ppm} \mathrm{NO}_{2}$ under either exposure condition.

We conclude that a $1 \mathrm{~h}$ exposure to 0.3 or $0.6 \mathrm{ppm} \mathrm{NO}_{2}$ has no clinically important effect on the airways of asthmatic adults or children, but that $0.6 \mathrm{ppm}$ may cause a slight increase in airway hyperresponsiveness.

Eur Respir J., 1996, 9, 910-918.
*Institute of Respiratory Medicine, Royal Prince Alfred Hospital, Sydney, NSW, Australia, **Dept of Medicine, University of Sydney, NSW, Australia. ${ }^{+}$CSIRO Division of Coal and Energy Technology, Sydney, NSW, Asutralia, ${ }^{++}$Dept of Safety Science, University of NSW, NSW, Australia.

Correspondence: A.J. Woolcock

Dept of Medicine

University of Sydney

Sydney

NSW 2006

Australia

Keywords: Airway hyperresponsiveness asthma

indoor air pollution

nitrogen dioxide

Received: June 61995

Accepted after revision January 221996

The study was supported by the National Health and Medical Research Council of Australia.
Nitrogen dioxide $\left(\mathrm{NO}_{2}\right)$ is a combustion by-product, which is produced in the indoor domestic environment by gas heaters and cookers [1]. Concern about the respiratory health effects of exposure to indoor $\mathrm{NO}_{2}$ has arisen as a result of epidemiological studies which have suggested that people living in homes with gas appliances have lower expiratory flow rates [2-4], and a higher rate of respiratory illness [3, 5-7], than those in homes with electrical appliances. The presence of gas appliances has been used as a marker for exposure to $\mathrm{NO}_{2}$. However, actual exposure levels have not usually been measured in these studies, and it is thus not possible to determine the $\mathrm{NO}_{2}$ concentration associated with adverse effects. In addition, because the outcomes have been assessed retrospectively it is not possible to establish a causal association between exposure and effect.

In order to determine safe levels and to set appropriate standards for indoor $\mathrm{NO}_{2}$, controlled studies, in which both the exposures and their effects can be monitored in detail, are required. Furthermore, it is essential, from the public health viewpoint, that such studies should include the most susceptible members of the population. It has been suggested that subjects with moderate-to-severe asthma, and especially asthmatic children, represent a susceptible subpopulation for the effects of nitrogen oxides [8].

Controlled studies of the effects of short-term exposure to $\mathrm{NO}_{2}$ on the symptoms and severity of asthma have not led to clear cut findings. Some studies of asthmatic subjects have shown effects at concentrations as low as $0.1 \mathrm{ppm}$ [9], while others have been unable to show any effect at concentrations as high as $4.0 \mathrm{ppm}$ [10]. The reasons for these conflicting findings are unclear but may include such factors as the severity of asthma in the subjects tested, whether the response was measured as changes in lung function or in airway hyperresponsiveness (AHR), and the means of administration of the $\mathrm{NO}_{2}$.

A potential source of differences between studies is variation in the nature of the exposure gas itself. Previous 
controlled studies of $\mathrm{NO}_{2}$ have used direct exposures, in which the test gas is a simple $\mathrm{NO}_{2}$ /air mixture. However, gas combustion produces nitrogen oxides in the form of two species, namely nitric oxide (NO) and nitrogen dioxide $\left(\mathrm{NO}_{2}\right)$. The relative proportions of these two products varies with the design and condition of the combustion appliance. These nitrogen oxides can then further react with water to produce nitrous acid $\left(\mathrm{HNO}_{2}\right)$ and nitric acid $\left(\mathrm{HNO}_{3}\right)$. As a consequence, in indoor environments where elevated levels of $\mathrm{NO}_{2}$ are found, a range of nitrogen compounds exist, of which $\mathrm{NO}_{2}$ can be a major component.

The aim of the present study was to examine the effects of $\mathrm{NO}_{2}$, at concentrations of 0.3 and $0.6 \mathrm{ppm}$, on asthmatic adults and children. In addition, in response to the ongoing discussion about the possible health effects of unflued gas heaters and their by-products, we examined the effects of the same $\mathrm{NO}_{2}$ concentrations, but included in the test atmospheres the combustion products, including the range of oxidized nitrogen species, emitted by a domestic unflued gas space heater. We report the effects of exposure to $\mathrm{NO}_{2}$, and other combustion by-products, on AHR, on symptoms and on lung function in adults and children with severe or moderate asthma.

\section{Methods}

\section{Subjects}

Subjects were recruited for the study through hospital out-patient clinics, by local advertising and through local schools. All subjects gave written informed consent, and for children written informed consent was given by parents. Ethics approval for the study was obtained from the Ethics Review Committee of the Central Sydney Health Service and from the NSW Department of Education for recruitment undertaken through schools.

Subjects were included in the study if they had a previous diagnosis of asthma and symptoms which required current therapy. In addition, subjects were required to have demonstrable airway hyperresponsiveness to histamine in the moderate or severe range (provocative dose of histamine causing a $20 \%$ fall in forced expiratory volume in one second (PD20FEV1) less than or equal to 1.5 umol histamine). Subjects were required not to use household gas heating for the duration of the study.

\section{Study design}

This was a double-blind study in which the order of exposures was randomized. Subjects were exposed for $1 \mathrm{~h}$ on five separate occasions, 1 week apart, to ambient air alone, $\mathrm{NO}_{2}$ and ambient air $(0.3$ and $0.6 \mathrm{ppm})$, and $\mathrm{NO}_{2}$ and combustion by-products $(0.3$ and $0.6 \mathrm{ppm})$. The investigators responsible for the assessment of the subjects were blind to the exposure conditions. A separate team of investigators, who had no contact at all with the subjects, were responsible for setting up and monitoring the exposures. The exposures were coded and this code was broken after the data were analysed.

On each test day, after measurement of baseline lung function, subjects with forced expiratory volume in one second $(\mathrm{FEV} 1)>60 \%$ predicted had airway responsiveness to histamine measured and were then allowed to recover spontaneously, without the aid of a bronchodilator, for $1 \mathrm{~h}$. After that, provided their lung function had returned to within $10 \%$ of baseline, they entered the exposure chamber. Subjects remained at rest in the chamber for $1 \mathrm{~h}$. At $15 \mathrm{~min}$ intervals during the exposure and for the hour following exposure, peak expiratory flow rate and symptom score were recorded. One hour after the end of the exposure period, airway responsiveness was again measured in all subjects with FEV1 $>60 \%$ predicted. During the week following each exposure, subjects kept a daily record of expiratory flow rates, symptoms and medication use. Airway responsiveness was measured at the end of this week. This measurement served a dual role - as an assessment of the long-term effect of the previous week's exposure and as a baseline for the new exposure undertaken that day.

\section{Nitrogen dioxide exposure}

A special "exposure room" was developed to enable exposures to known concentrations of $\mathrm{NO}_{2}$ to be carried out. The $3.9 \times 2.6 \mathrm{~m}$ exposure room was designed to reproduce as far as possible a normal home environment and included an acrylic carpet, painted walls, a wood and metal coffee table and four vinyl lounge chairs. There was a window, which was kept closed, and a controlled ventilation system. The test atmospheres were generated in an adjoining room, where $\mathrm{NO}_{2}$ was dispensed in small aliquots from a cylinder of pure material and mixed with ambient air to obtain the required concentrations. These were conditioned to the appropriate temperature and relative humidity and then circulated to the exposure room. The concentration of nitrogen oxides in the exposure room was assessed from samples taken at various points in the room. The exposure room was evaluated to demonstrate uniformity of mixing, the performance of the $\mathrm{NO}_{2}$ supply system and to determine the air exchange rate. Two types of exposure tests at each $\mathrm{NO}_{2}$ concentration were undertaken. In the first, $\mathrm{NO}_{2}$ was mixed with ambient air drawn from outside the building. In the second type of exposure, all the products derived from the operation of a gas space heater (Vulcan Quasar Flueless gas space heater, Model 8302 T18), were mixed with additional $\mathrm{NO}_{2}$ and ambient air to match the $\mathrm{NO}_{2}$ concentrations in the first type of exposure. For all exposures, outside air was introduced to the room at a rate of six air changes per hour.

The air inside the room and the ambient air were continuously monitored for $\mathrm{NO}_{2}$ and $\mathrm{NO}$ (Monitor Laboratories Nitrogen Oxides Analyser, Model 8840). During ambient air only exposures, the $\mathrm{NO}_{2}$ and NO concentrations were both $0.02 \pm 0.01 \mathrm{ppm}$ (mean $\pm \mathrm{SD}$ ). When pure $\mathrm{NO}_{2}$ was added to the ambient air to give concentrations of $0.3 \pm 0.03$ and $0.6 \pm 0.04 \mathrm{ppm}$, the respective NO concentrations were $0.09 \pm 0.02$ and $0.08 \pm 0.02 \mathrm{ppm}$. Operating the gas heater, without any additional $\mathrm{NO}_{2}$, gave room concentrations of $0.23 \pm 0.03 \mathrm{ppm} \mathrm{NO}$ and $1.0 \pm 0.04 \mathrm{ppm}$ NO. When these combustion products were augmented with pure $\mathrm{NO}_{2}$, to give concentrations of $0.3 \pm 0.03$ and $0.61 \pm 0.04 \mathrm{ppm}$, the respective NO concentrations were $1.0 \pm 0.03 \mathrm{ppm}$ and $1.12 \pm 0.05 \mathrm{ppm}$. The concentrations 
of $\mathrm{CO}$ and $\mathrm{CO}_{2}$ were also measured during a subset of the test exposures. During the operation of the gas heater, $\mathrm{CO}$ remained below $5 \mathrm{ppm}$ in all samples, and the mean $\mathrm{CO}_{2}$ was $2022 \pm 71 \mathrm{ppm}$. The relative humidity inside the room was maintained at $55 \pm 5 \%$ and the temperature at $22 \pm 2^{\circ} \mathrm{C}$ for both types of exposure by using an air conditioner mounted within the air distribution system.

\section{Symptoms and lung function during exposure}

Respiratory symptoms were recorded at rest prior to exposure, and at $15 \mathrm{~min}$ intervals throughout the exposure and during the hour following exposure. Subjects recorded symptom scores for wheeze, shortness of breath and cough on a modified Borg scale [11] $(0=$ no symptoms; $10=$ maximal symptoms), and the scores were summed to give a total symptom score for each $15 \mathrm{~min}$ interval. Peak expiratory flow rate (PEFR) was recorded at the same times using an Assess peak flow meter (HealthScan Products, NJ, USA). The best of three attempts was recorded. Peak flow rates were recorded as percentage of predicted values for adults [12] and children [13].

A Vitalograph wedge bellows spirometer (Vitalograph Ltd, Bucks, UK) was used to measure forced vital capacity (FVC) and FEV1 immediately before and $1 \mathrm{~h}$ after exposure. The highest of two values for FEV1 repeatable to within $100 \mathrm{~mL}$ was recorded. FVC and FEV1 are shown as a percentage of predicted values for adults [14] and children [15].

\section{Airway responsiveness}

Airway responsiveness was assessed using histamine inhalation tests performed according to the method of YAN et al. [16]. Briefly, histamine was administered to the subject via a handheld DeVilbiss No. 45 plastic nebulizer, in doubling doses ranging 0.03-7.8 $\mu \mathrm{mol}$, until the FEV1 fell by $20 \%$ or more. A dose response curve was plotted and from this curve the dose causing a $20 \%$ fall in FEV1 (PD20FEV1) was read by interpolation. All aerosol medication was withheld for $6 \mathrm{~h}$ and theophylline for $12 \mathrm{~h}$ prior to testing.

\section{Asthma severity in the week following exposure}

During the week following each exposure, the following information was recorded daily by all subjects.
Peak expiratory flow rate. Expiratory flow rate was measured, using an Assess peak flow meter, in the morning and at night, before and after bronchodilator, if used. Morning peak flow, before bronchodilator, was recorded as percentage of the highest value measured during the 5 week study (recent best). Mean morning prebronchodilator PEF, as percentage recent best, was calculated for each subject for each week [17] and used to calculate a PEF score (table 1).

Symptom scores. Symptom scores for wheeze, cough and shortness of breath were recorded daily using the following scoring system: $0=$ no symptoms; $1=$ occasional symptoms which do not interfere with normal activity and do not require extra medication; $2=$ symptoms which do not interfere with normal activity, provided extra medication is taken; 3 = symptoms which interfere with normal activity despite extra medication; and 4 = symptoms which make normal activity impossible. The highest score for any symptom on any day was taken as the score for that day. The frequency and severity of daily symptom scores during the week was used to calculate a weekly symptom score (table 1).

Treatment. The names and doses of all medications taken each day were recorded. The number of occasions on which medication requirements increased was counted and a score given for each week (table 1).

A composite asthma severity score was calculated from the diary card data. Each component of the score (PEF, as percentage recent best, symptoms and increases in medication use) contributed up to four points to a maximum composite score of 12 (table 1).

\section{Data analysis}

Effects on airway hyperresponsiveness. To determine the effect of $\mathrm{NO}_{2}$ on airway hyperresponsiveness, the difference between PD20FEV1 values from the histamine challenge performed $1 \mathrm{~h}$ prior to the exposure test and the challenge performed $1 \mathrm{~h}$ after the exposure was calculated and expressed in terms of doubling doses. The differences for all exposures were compared by analysis of variance (ANOVA) for repeated measures. A similar analysis was performed, comparing PD20FEV1 values from the pre-exposure challenge with those from the challenge test 1 week after exposure, to examine effects on AHR over the week following each exposure.

Table 1. - Asthma severity score

\begin{tabular}{|c|c|c|c|c|c|}
\hline & 0 & 1 & 2 & 3 & 4 \\
\hline $\begin{array}{l}\text { Symptoms score } \\
\text { frequency and severity }\end{array}$ & None & 1 on 3 days or less & $\begin{array}{l}1 \text { on } \geq 4 \text { days or } \\
2 \text { on } \leq 2 \text { days }\end{array}$ & $\begin{array}{c}2 \text { on } \geq 3 \text { days or } \\
3 \text { on } \leq 2 \text { days }\end{array}$ & $\begin{array}{c}3 \text { on } \geq 3 \text { days or } \\
4 \text { on any day }\end{array}$ \\
\hline $\begin{array}{l}\text { Increased medication } \\
\text { change from usual }\end{array}$ & No change & $\begin{array}{c}\text { BD/SCG } \\
\text { on } 1-3 \text { days }\end{array}$ & $\begin{array}{l}\mathrm{BD} / \mathrm{SCG} \\
\text { on } \geq 4 \text { days }\end{array}$ & $\begin{array}{l}\text { Steroid aerosol } \\
1 \text { or more days }\end{array}$ & $\begin{array}{l}\text { Oral steroid } \\
1 \text { or more days }\end{array}$ \\
\hline $\begin{array}{l}\text { pre-BD PEF a.m. } \\
\% \text { recent best }\end{array}$ & $>93$ & $85-93$ & $78-85$ & $70-77$ & $<70$ \\
\hline
\end{tabular}

BD: bronchodilator; SCG: sodium cromoglycate; PEF: peak expiratory flow. 
Table 2. - Details of subjects at entry into study

\begin{tabular}{|c|c|c|c|c|c|c|c|}
\hline $\begin{array}{l}\text { Subject } \\
\text { No. }\end{array}$ & $\begin{array}{l}\text { Sex } \\
\mathrm{M} / \mathrm{F}\end{array}$ & $\begin{array}{l}\text { Age } \\
\text { yrs }\end{array}$ & $\begin{array}{l}\text { Height } \\
\mathrm{cm}\end{array}$ & $\begin{array}{l}\text { FEV1 } \\
\% \text { pred }\end{array}$ & $\begin{array}{c}\mathrm{FVC} \\
\% \text { pred }\end{array}$ & $\begin{array}{l}\mathrm{PD} 20 \mathrm{FEV} 1 \\
\mu \mathrm{mol}\end{array}$ & $\begin{array}{l}\text { Current } \\
\text { treatment }\end{array}$ \\
\hline \multicolumn{8}{|l|}{ Adults } \\
\hline 1 & $\mathrm{~F}$ & 24 & 166 & 78 & 82 & 0.15 & $\mathrm{~S}$ \\
\hline 2 & $\mathrm{~F}$ & 40 & 167 & 99 & 105 & 0.29 & S, BDP \\
\hline 4 & M & 65 & 161 & 100 & 96 & 1.2 & S, B \\
\hline 6 & M & 65 & 180 & 68 & 84 & 0.3 & S, BDP \\
\hline 8 & $\mathrm{~F}$ & 19 & 169 & 66 & 80 & 0.06 & S, BDP \\
\hline 9 & $\mathrm{~F}$ & 33 & 161 & 92 & 92 & 0.64 & $\mathrm{~T}, \mathrm{~B}$ \\
\hline 11 & $\mathrm{~F}$ & 27 & 160 & 76 & 76 & 0.25 & S, BDP, TL \\
\hline 18 & $\mathrm{~F}$ & 21 & 168 & 73 & 91 & 0.18 & S, B \\
\hline \multirow[t]{2}{*}{22} & F & 34 & 158 & 84 & 109 & 0.2 & S, BDP, SC \\
\hline & $2 / 7$ & 36 & & & & & \\
\hline \multicolumn{8}{|l|}{ Children } \\
\hline 3 & $\mathrm{~F}$ & 12 & 146 & 68 & 70 & 0.33 & S, BDP \\
\hline 7 & $\mathrm{~F}$ & 14 & 154 & 104 & 113 & 1.26 & $\mathrm{~S}, \mathrm{IP}, \mathrm{SC}$ \\
\hline 13 & M & 13 & 162 & 59 & 72 & 0.39 & S, SC \\
\hline 14 & M & 14 & 150 & 79 & 100 & 0.72 & S, BDP, SC \\
\hline 15 & $\mathrm{~F}$ & 15 & 164 & 105 & 112 & 0.21 & $\mathrm{~S}$ \\
\hline 16 & M & 12 & 148 & 63 & 79 & 0.13 & S \\
\hline 17 & $\mathrm{~F}$ & 10 & 142 & 91 & 113 & 1.14 & S, BDP, SC \\
\hline 19 & M & 7 & 128 & 85 & 98 & 0.49 & S, BDP \\
\hline 20 & $\mathrm{~F}$ & 14 & 152 & 84 & 106 & 0.24 & $\mathrm{~T}, \mathrm{SC}, \mathrm{B}$ \\
\hline 24 & M & 9 & 131 & 114 & 110 & 1.5 & T, B \\
\hline \multirow[t]{2}{*}{25} & $\mathrm{M}$ & 8 & 128 & 118 & 111 & 1.5 & $\mathrm{~T}, \mathrm{SC}, \mathrm{B}$ \\
\hline & $6 / 5$ & 12 & & & & & \\
\hline
\end{tabular}

M: male; F: female; FEV1: forced expiratory volume in one second; FVC: forced vital capacity; \% pred: percentage of predicted value; $\mathrm{PD}_{20 \mathrm{FEV}}$ : provocative dose of histamine causing a $20 \%$ fall in FEV1; S: salbutamol; SC: sodium cromoglycate; B: budesonide; TL: theophylline; T: terbutaline; BDP: beclomethasone dipropionate; IP: ipratropium bromide.

Effects on symptoms and lung function. The immediate effects of $\mathrm{NO}_{2}$ were determined by examining changes in symptoms and lung function during and immediately after the exposure period. For each subject, the changes from baseline in symptom score, for the sum of the three symptoms, and for PEF, as a percentage of baseline value, were calculated. Mean changes for the group at each measurement point were plotted against time. For each subject, the change in PEF and symptoms score during and after each exposure was summarized as mean change and as maximum change. The differences between exposures were determined by repeated measures ANOVA and paired t-test.

Effects on severity of asthma. The effects of $\mathrm{NO}_{2}$ on the severity of asthma were examined in the week following each exposure. The mean composite asthma severity score and mean morning peak flow were calculated for the week following each exposure and the values compared by ANOVA for repeated measures. The distribution of asthma severity scores after the room air exposure did not differ significantly from normal (Shapiro Wilk statistic $=0.96 ; \mathrm{p}=0.58)$.

\section{Results}

Twenty three subjects agreed to participate, of whom 20 (9 adults and 11 children) completed the study. Their details are shown in table 2 . Three adult subjects withdrew: one due to worsening asthma, unrelated to the study procedures; one due to an improvement in asthma severity, so that he no longer met the inclusion criteria; and the third because of personal reasons. Of the subjects who completed the study, all were atopic, one adult had smoked cigarettes in the past, the rest were lifelong nonsmokers. All subjects were using one or more bronchodilating aerosols or dry powder inhalers, and most were taking inhaled corticosteroids. Four subjects had had previous short courses of oral corticosteroids, and kept a supply at home for use if required. None of the subjects were taking regular oral corticosteroids at the time of this study.

Baseline lung function, prior to each histamine challenge or $\mathrm{NO}_{2}$ exposure, did not vary significantly throughout the study. Table 3 shows mean (95\% confidence

Table 3. - FEV1, as percentage predicted, measured immediately before each $\mathrm{NO}_{2}$ exposure and before the histamine challenges performed $1 \mathrm{~h}$ before and $1 \mathrm{~h}$ after each exposure

\begin{tabular}{lccc}
\hline & \multicolumn{3}{c}{ FEV1\% pred } \\
\cline { 2 - 4 } & $\begin{array}{c}1 \text { h before } \\
\mathrm{NO}_{2}\end{array}$ & $\begin{array}{c}\text { Immediately } \\
\text { before } \mathrm{NO}_{2}\end{array}$ & $\begin{array}{c}1 \mathrm{~h} \text { after } \\
\mathrm{NO}_{2}\end{array}$ \\
\hline Room air & $87.2(6.9)$ & $86.3(7.3)$ & $86.3(7.5)$ \\
$0.3 \mathrm{ppm} / \mathrm{RA}^{*}$ & $87.7(7.5)$ & $85.1(6.4)$ & $86.5(7.5)$ \\
$0.6 \mathrm{ppm} / \mathrm{RA}^{*}$ & $87.7(8.3)$ & $83.1(8.4)$ & $83.1(9.5)$ \\
$0.3 \mathrm{ppm} / \mathrm{GH}^{\#}$ & $85.4(7.7)$ & $83.8(7.1)$ & $85.1(8.4)$ \\
$0.6 \mathrm{ppm} / \mathrm{GH}^{\#}$ & $83.8(7.8)$ & $82.3(7.6)$ & $84.3(7.7)$ \\
\hline
\end{tabular}

Values are presented as mean and $95 \%$ confidence interval in parenthesis. *: $\mathrm{NO}_{2}$ plus room air (RA); \#: $\mathrm{NO}_{2}$ plus combustion by-products from gas heater $(\mathrm{GH})$. FEV1: forced expiratory volume in one second; $\%$ pred: percentage of predicted value. 
Table 4. - Effects of $\mathrm{NO}_{2}$ in 9 adults and 11 children

\begin{tabular}{|c|c|c|c|c|c|c|}
\hline & & Room air & $\begin{array}{l}0.3 \mathrm{ppm} \\
\mathrm{NO}_{2}+\mathrm{RA}^{*}\end{array}$ & $\begin{array}{c}0.6 \mathrm{ppm} \\
\mathrm{NO}_{2}+\mathrm{RA}^{*}\end{array}$ & $\begin{array}{l}0.3 \mathrm{ppm} \\
\mathrm{NO}_{2}+\mathrm{GH}^{\#}\end{array}$ & $\begin{array}{c}0.6 \mathrm{ppm} \\
\mathrm{NO}_{2}+\mathrm{GH}^{\#}\end{array}$ \\
\hline \multicolumn{7}{|c|}{ On the day of each exposure } \\
\hline \multirow[t]{2}{*}{$\triangle \mathrm{AHR} D \mathrm{D}$} & Adult & $0.44(0.51)$ & $0.07(0.66)$ & $-0.40(0.61)$ & $-0.12(1.1)$ & $0.59(0.63)$ \\
\hline & Child & $0.39(0.48)$ & $-0.04(0.44)$ & $-0.61(0.73)$ & $-0.14(0.67)$ & $0.19(0.70)$ \\
\hline \multirow{2}{*}{$\triangle \mathrm{PEF} \%$} & Adult & $-3.9 \quad(5.5)$ & $3.5 \quad(4.3)$ & $-5.4 \quad(6.5)$ & $1.6 \quad(4.7)$ & $2.4 \quad(3.7)$ \\
\hline & Child & $2.5 \quad(5.9)$ & $-0.11(3.4)$ & $1.5 \quad(4.2)$ & $4.4 \quad(3.3)$ & $5.7 \quad(7.3)$ \\
\hline \multirow{2}{*}{$\begin{array}{l}\Delta \text { Symptom } \\
\text { score }\end{array}$} & Adult & $0.01(0.38)$ & $-0.06(0.5)$ & $0.39(0.59)$ & $-0.56(1.2)$ & $-0.43(0.6)$ \\
\hline & Child & $-0.02(0.26)$ & $-0.35(0.5)$ & $-0.71(0.74)$ & $-0.30(0.43)$ & $-0.23(0.5)$ \\
\hline \multicolumn{7}{|c|}{ During the week following each exposure } \\
\hline \multirow{2}{*}{$\begin{array}{l}\text { Severity } \\
\text { score }\end{array}$} & Adult & $4.38(1.5)$ & $4.78(1.6)$ & $4.11(0.9)$ & $4.56(1.5)$ & $5.50(1.9)$ \\
\hline & Child & $4.20(1.3)$ & $4.00(1.0)$ & $5.70(2.1)$ & $4.45(1.3)$ & 5.09 (1.7) \\
\hline \multirow{2}{*}{$\begin{array}{l}\mathrm{PEF} \\
\% \text { best }\end{array}$} & Adult & $80.8 \quad(4.1)$ & $80.6 \quad(5.1)$ & $80.1 \quad(4.5)$ & $80.1 \quad(5.0)$ & $78.8 \quad(6.2)$ \\
\hline & Child & $78.4 \quad(5.1)$ & $81.6 \quad(4.5)$ & $78.0 \quad(6.7)$ & $81.8 \quad(4.1)$ & $80.1 \quad(4.3)$ \\
\hline
\end{tabular}

Values are presented as mean, and 95\% confidence interval in parenthesis. $\triangle$ AHR: difference in airway hyperresponsiveness (doubling dose (DD) change in PD20FEV1); $\triangle \mathrm{PEF}$ : difference in peak expiratory flow during and $1 \mathrm{~h}$ after exposure, as percentage change from immediately before exposure; $\Delta$ Symptom score: difference in summed Borg scores between values immediately before exposure and those during and $1 \mathrm{~h}$ after exposure. Asthma severity score and PEF (as percentage of recent best) were calculated from diary cards during the week following each exposure. For definitions see legend to table 2. $\mathrm{NO}_{2}$ plus room air (RA); $\mathrm{NO}_{2}$ plus combustion by-products from gas heater $(\mathrm{GH})$.

interval $(95 \% \mathrm{CI}))$ FEV1 values as percentage predicted, measured on each of the five test days before the first histamine challenge, immediately before entering the exposure chamber, and before the second histamine challenge $1 \mathrm{~h}$ after leaving the exposure chamber.

Effects of $\mathrm{NO}_{2}$ in room air on airway hyperresponsiveness. The effect of $\mathrm{NO}_{2}$ on airway hyperresponsiveness was determined by examining changes in PD20FEV1 from the histamine challenge performed $1 \mathrm{~h}$ prior to the exposure and the challenge performed $1 \mathrm{~h}$ after the exposure. The changes in PD20FEV1 values (as mean and 95\% CI of the difference between the two PD20FEV1 values) are shown separately for adults and children in table 4 and as combined data in figure 1. A positive value indicates an improvement in AHR after exposure and a negative value indicates a worsening in AHR. There were no significant differences between adults and children. Changes in PD20FEV1 after exposure differed between the three exposure days $(\mathrm{p}<0.02)$. The mean difference in postexposure change in PD20FEV1 between room air and $0.6 \mathrm{ppm}$ was 0.92 (95\% CI 0.28-1.56) doubling doses $(\mathrm{p}=0.006)$. The other pairwise comparisons were not significant (room air vs 0.3 ppm: $0.40(-0.09-0.9)$ doubling doses; 0.3 vs 0.6 ppm: $0.52(-0.11-1.15)$ doubling doses; $\mathrm{p}=0.10)$. There was no significant correlation between change in PD20FEV1 after $0.6 \mathrm{ppm} \mathrm{NO}_{2}$ and the baseline PD20FEV1 value $(r=-0.38$; df 16$)$.

Effects of $\mathrm{NO}_{2}$ in room air on symptoms and peak expiratory flow. The acute effects of $\mathrm{NO}_{2}$ were determined by examining changes in symptoms and PEF from the baseline measured immediately prior to entering the chamber, during and for $1 \mathrm{~h}$ after the exposure period. Prior to the room air exposure, mean $( \pm 95 \%$ CI $)$ symptom scores and PEF \% pred, values were $0.75 \pm 0.82$ and $85.0 \pm 6.7 \%$, respectively, in adults, and $0.23 \pm 0.20$ and $93.0 \pm 10.6 \%$, respectively, in children. Mean changes in

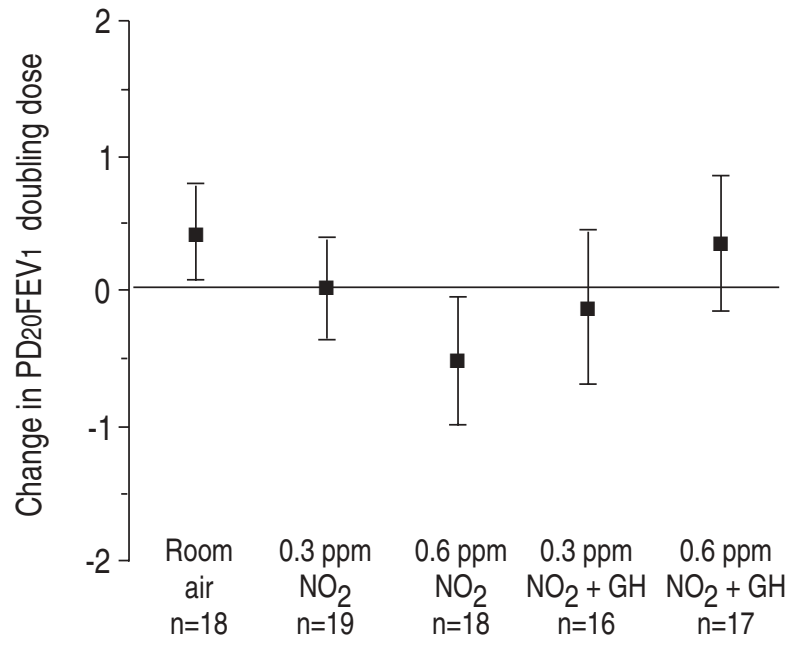

Fig. 1. - Change in airway hyperresponsiveness (AHR) from baseline to $1 \mathrm{~h}$ after exposure, shown as mean and $95 \%$ confidence intervals of the doubling dose difference between the two PD20FEV1 values. Data for adults and children are combined. The solid line at zero indicates no change. A positive value indicates improved AHR after exposure and a negative value indicates worse $\mathrm{AHR}$. $\mathrm{PD} 20 \mathrm{FEV} 1$ : provocative dose of histamine causing a $20 \%$ fall in forced expiratory volume in one second; GH: plus combustion by-products from gas heater.

PEF and symptom scores from baseline, for each exposure, in adults and children are shown in table 4. Mean changes in symptom scores and PEF values did not differ significantly from zero and there were no significant differences between adults and children. There were no significant differences between the three exposure days in PEF, expressed as either the average change $(\mathrm{p}=0.46)$ or the maximum change $(\mathrm{p}=0.51)$, or in symptom score, expressed as either average change $(\mathrm{p}=0.42)$ or maximum change $(p=0.29)$. Figure 2 shows mean changes in $\mathrm{PEF}$, as percentage fall during and $1 \mathrm{~h}$ after exposure to room air and $0.6 \mathrm{ppm} \mathrm{NO}_{2}$. 


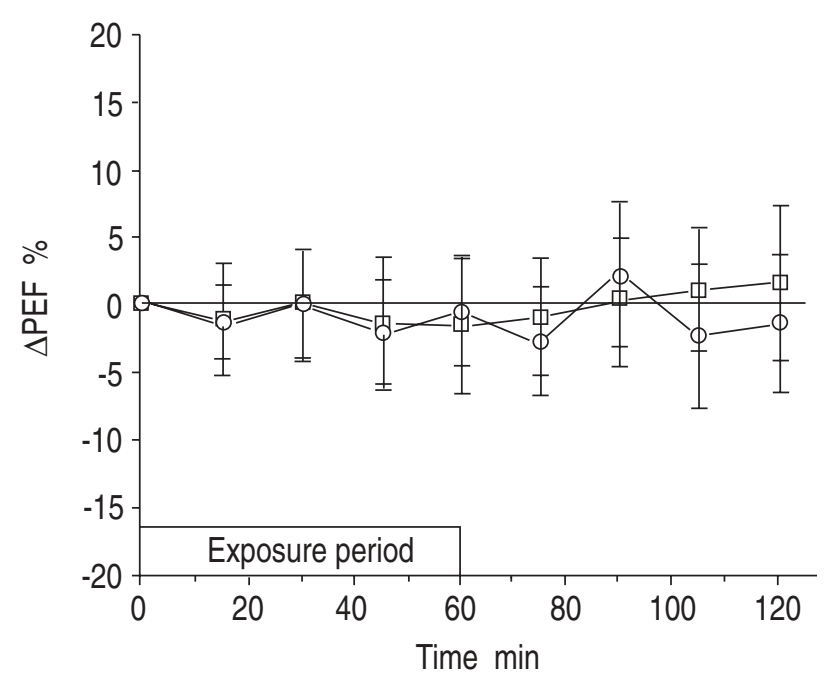

Fig. 2. - Mean changes (95\% confidence interval) in peak expiratory flow $(\triangle \mathrm{PEF})$, as percentage fall from the baseline measured immediately prior to entering the chamber, at $15 \mathrm{~min}$ intervals during and for $1 \mathrm{~h}$ after exposure to room air and to $0.6 \mathrm{ppm} \mathrm{NO}_{2}$. The solid line at zero indicates no change. $\square-$ : room air; $\longrightarrow-\mathrm{O}: 0.6 \mathrm{ppm} \mathrm{NO}_{2}$.

Effects of $\mathrm{NO}_{2}$ in room air on severity of asthma. The effects of $\mathrm{NO}_{2}$ on the severity of asthma were examined in the week following each exposure. The asthma severity score, which was calculated from the diary card data, was not significantly different following any of the active exposures from that following room air. Figure 3 shows the mean $(95 \% \mathrm{CI})$ differences between the scores following room air and those following each of the active exposures. Table 4 shows mean asthma severity scores and mean morning peak flow, as percentage of recent best, after each exposure in adults and children.

There were no effects on AHR a week after any of the exposures. Figure 4 shows changes in AHR, as the doubling dose difference between PD20FEV1 values, from baseline to one week after exposure.

Effects of $\mathrm{NO}_{2}$ plus combustion by-products. Addition to the test atmospheres of the combustion by-products from the gas heater had no effect on any of the lung function variables described above. Changes in AHR in

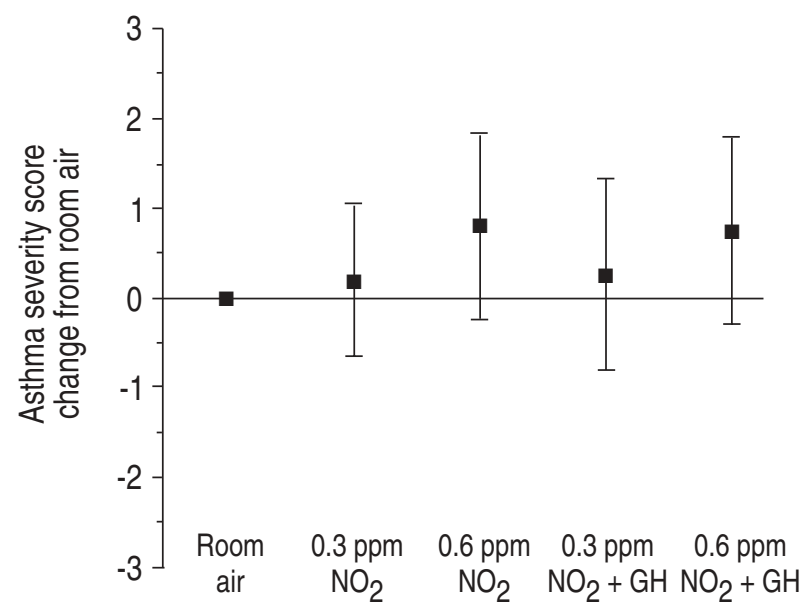

Fig. 3. - Mean (95\% confidence interval) of the difference in asthma severity score during the week following each exposure from that following room air (see text for details of the asthma severity score). $\mathrm{GH}$ : plus combustion by-products from gas heater.

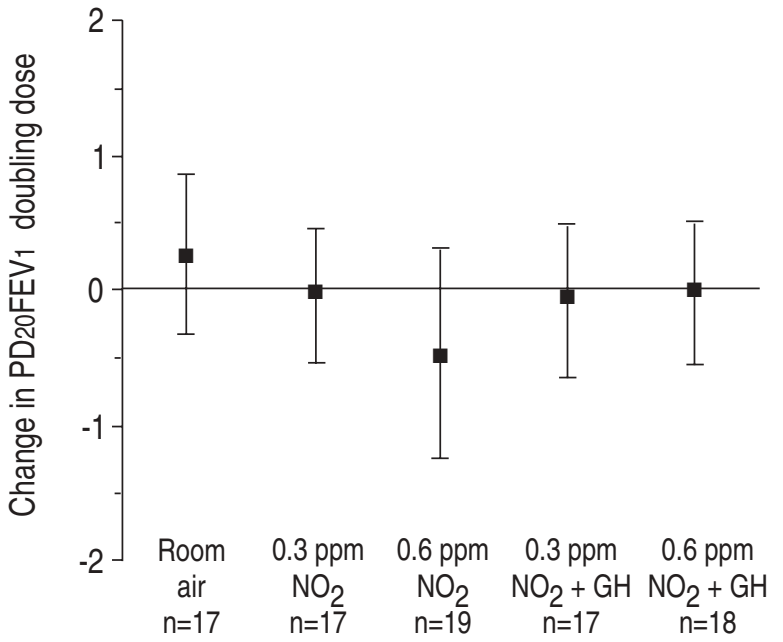

Fig. 4. - Change in airway hyperresponsiveness (AHR) from baseline to 1 week after exposure shown as mean and 95\% confidence intervals of the doubling dose difference between the two PD20FEV 1 values. The solid line at zero indicates no change. A positive value indicates improved AHR after exposure and a negative value indicates worse AHR. For definitions see legend to figure 1.

the exposures which included the gas heater outputs are shown in figures 1 and 4. Repeated measures ANOVA showed that the effect of the addition of the combustion by-products differed between the two levels of $\mathrm{NO}_{2}$ exposure $(\mathrm{p}=0.01)$. At $0.3 \mathrm{ppm}$, the heater caused a $0.14(95 \%$ CI -0.22-0.51) relative increase in PD20FEV1, whereas at $0.6 \mathrm{ppm}$ the heater caused a $0.86(0.25-1.49)$ relative decrease in PD20FEV1. The slight worsening of AHR which was found after $0.6 \mathrm{ppm} \mathrm{NO}$ in room air was not found in the presence of the gas heater by-products. Figure 5 compares the changes in PEF, as percentage change from baseline, with and without the gas heater output during exposures to $0.3 \mathrm{ppm} \mathrm{NO}_{2}$ (fig. 5a) and $0.6 \mathrm{ppm}$ $\mathrm{NO}_{2}$ (fig. 5b). During exposure to $0.6 \mathrm{ppm} \mathrm{NO}$, PEF values were higher in the presence of the gas heater (mean difference in PEF, percentage change from baseline, $8.02 \pm 7.0 \% ; \mathrm{p}=0.03$ ). The gas heater did not influence the response to $0.3 \mathrm{ppm} \mathrm{NO}_{2}$ (mean difference in $\mathrm{PEF}$, percentage change from baseline, $1.6 \pm 3.5 \%$; $\mathrm{p}=0.35$ ).

\section{Discussion}

In this study, a $1 \mathrm{~h}$ exposure to nitrogen dioxide, at either 0.3 or $0.6 \mathrm{ppm}$ had no effect on peak expiratory flow or symptoms in asthmatic subjects. There was a small increase in airway hyperresponsiveness (AHR) $1 \mathrm{~h}$ after exposure to $0.6 \mathrm{ppm} \mathrm{NO}_{2}$ but this increase was not present when combustion by-products from a gas heater were included in the test atmosphere. There was no effect of $0.3 \mathrm{ppm} \mathrm{NO}_{2}$.

In order to establish safe levels for $\mathrm{NO}_{2}$ for the community as a whole, it is essential to consider its effects on those most at risk. In this study, we examined the effect of realistic exposure situations in people with relatively severe asthma, with AHR in the moderate to severe range. Asthma of this severity is found in approximately $3 \%$ of the Australian population $[18,19]$. The subjects in this study were reasonably representative of this population of asthmatics, in that all required daily treatment, and most were taking inhaled corticosteroids. It is 

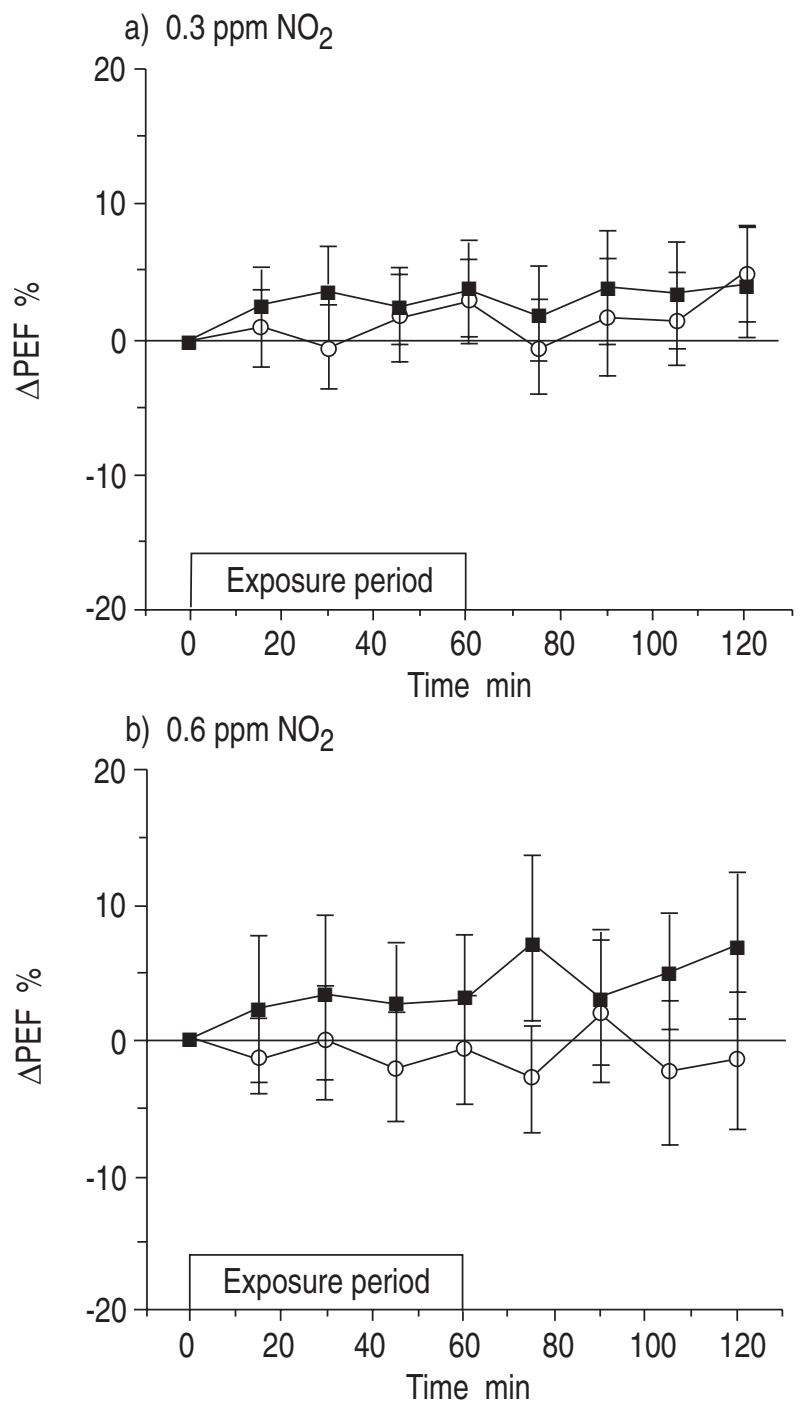

Fig. 5. - Mean (95\% confidence interval) changes in peak expiratory flow $(\triangle \mathrm{PEF})$, as percentage fall from baseline, during exposures to: a) $0.3 \mathrm{ppm} \mathrm{NO}$; and b) $0.6 \mathrm{ppm} \mathrm{NO}$, mixed with room air (RA) or with the output of the gas heater $(\mathrm{GH})$. The line at zero indicates no change. $-1: \mathrm{NO}_{2}+$ room air; $-1 \mathrm{NO}_{2}+$ output of gas heater.

possible that inhaled corticosteroids could modify responses to $\mathrm{NO}_{2}$ exposure, but, with only five subjects not taking inhaled corticosteroids, the present study was unable to assess such an effect. There was no correlation between severity of baseline AHR and the change in AHR after exposure to $0.6 \mathrm{ppm} \mathrm{NO} \mathrm{N}_{2}$, suggesting that subjects with more severe AHR do not have increased susceptibility to the effects of $\mathrm{NO}_{2}$. There was no evidence in the present study that the responses of adults and children differed, although previous studies have suggested that children may be more susceptible to $\mathrm{NO}_{2}$ [8].

The study was carried out in the warm summer months, from November 1992 to May 1993. Subjects were unlikely to have been exposed to any type of domestic heating during this period, but the four subjects who had gas heaters installed at home were instructed not to use them for the duration of the study. We could not control for use of gas cookers. However, exposure to gas from cookers is likely to have occurred randomly throughout the study, and thus have no systematic effect on the results. Most subjects were atopic to house dust mites, which are at high levels year round in Sydney, so the findings are unlikely to be confounded by any seasonal effects.

A number of studies have shown that exposure to $\mathrm{NO}_{2}$, in the range 0.1-0.5 ppm, may cause an increase in AHR in asthmatic subjects [9, 20-24]. However, some of these positive findings have come from studies with dubious statistical analyses $[9,22]$, and other studies in the same concentration range have not reproduced the findings $[25,26]$. A recent meta-analysis of 25 controlled clinical trials suggested that AHR increases in asthmatic subjects after exposure to concentrations of $\mathrm{NO}_{2}$ below 1.0 ppm and also in normal subjects after exposure to concentrations above $1.0 \mathrm{ppm}$ [27]. In the present study, there appeared to be a small increase in AHR after exposure to $0.6 \mathrm{ppm} \mathrm{NO}_{2}$. However, the increase was due to a change of only half a doubling dose in PD20FEV1, from a mean of 0.42 to $0.32 \mu \mathrm{mol}$. In previous studies which have shown increases in AHR, where it is possible to estimate the size of the change from the published data, changes have ranged from a half [22] to one doubling dose or concentration $[9,20]$. The clinical relevance of such changes is uncertain, since they are close to the limits of reproducibility of most tests of AHR. This may be especially true in the present study, when exposure to $0.6 \mathrm{ppm} \mathrm{NO}_{2}$, including the by-products from the gas heater, had no effect on AHR.

In this study, we controlled for the day to day variability in AHR by doing two histamine challenges on the same day, $1 \mathrm{~h}$ before and $1 \mathrm{~h}$ after the $\mathrm{NO}_{2}$ exposure. From figure 1 it can be seen that there was a small but significant decrease in AHR after room air exposure, suggesting that there may be a slight tachyphylaxis. Changes in AHR have been analysed both as absolute change from the daily baseline and as a comparison with changes during the room air control exposure. Only the $0.6 \mathrm{ppm}$ exposure caused a change in AHR which differed significantly from that after the room air control. There were no significant differences in baseline lung function between study days or, more importantly, between the pre- and postexposure histamine challenges. However, although not statistically significant, on the 0.6 $\mathrm{ppm} / \mathrm{room}$ air exposure day, baseline lung function $1 \mathrm{~h}$ before and $1 \mathrm{~h}$ after exposure differed by approximately $4.6 \%$. This was due, in part, to the two subjects whose lung function postexposure was too low to allow a histamine challenge. However, there was no significant correlation $(r=0.28)$ between the change in baseline lung function and change in AHR.

If exposure to $\mathrm{NO}_{2}$ caused inflammatory changes in the airways, it is likely that such an exposure would be accompanied by an increase in the severity of asthma during the days immediately following the exposure. In the present study, one child suffered an attack of asthma on the night following $0.6 \mathrm{ppm} \mathrm{NO}_{2}$. We were unable to measure her airway hyperresponsiveness on the day of this exposure due to her poor lung function. This child had severe asthma and had had several attacks requiring treatment with short courses of oral steroids during the previous year. It is not clear if this attack was related to the $\mathrm{NO}_{2}$ exposure, but she had no untoward effects after 
0.6 ppm $\mathrm{NO}_{2}$ mixed with the combustion by-products. In the rest of the group, there were no significant changes in the severity of asthma, assessed as symptoms, medication use or lung function, in the days following exposure. The use of a composite asthma score to analyse the diary card data has allowed us to compensate for changes in symptoms or lung function associated with changes in medication, which may be missed when the components are analysed separately.

In this study, exposure to $\mathrm{NO}_{2}$ did not induce any acute asthmatic responses, as evidenced by the symptom scores and PEF measurements recorded during and for $1 \mathrm{~h}$ after each exposure. The largest mean fall in PEF was $3( \pm 4.1)$ $\%$, during the $0.6 \mathrm{ppm} \mathrm{NO}_{2}$ exposure, which was not statistically significant. Detection of smaller lung function changes would require larger sample sizes or more sensitive lung function tests. Evidence from previous controlled exposures suggests that $\mathrm{NO}_{2}$ has little effect on lung function, even in susceptible populations of asthmatic subjects. Controlled exposures to $\mathrm{NO}_{2}$, in concentrations ranging from $0.1 \mathrm{ppm}$ [24] to $4 \mathrm{ppm}$ [10] have shown little or no direct effect on expiratory flow rates or on more sensitive tests, such as airway resistance.

Oxides of nitrogen which are produced in normal indoor environments are complex chemical mixtures which interact with their environment. There are potential interactions between the components of the complex mixtures, which may modify their effects on the respiratory system. Many previous studies of the effects of $\mathrm{NO}_{2}$ have used highly controlled exposure methods, using direct exposures through a mouthpiece [28, 29] or environmental chambers $[20,23,26,30]$. While such studies help to isolate and identify important effects of pollutants, they bear little relationship to real world exposures. The present study attempted to mimic real life exposures in two ways: 1) the nature of the exposure chamber; and 2) increasing the complexity of the test atmospheres by including combustion by-products from an unflued gas heater. The exposure chamber contained surfaces and furnishings which resembled the environment in which people are most likely to be exposed. Whilst it is likely that the test gases interacted with this environment, there was sufficient throughput of air to ensure that the $\mathrm{NO}_{2}$ content was maintained at the appropriate level. Inclusion of the combustion by-products in the test atmospheres produced levels of nitric oxide (NO) of $1.1 \mathrm{ppm}$. This is a relatively low concentration, but at higher concentrations NO might be expected to cause some bronchodilation [31]. It is possible that an adverse effect of $\mathrm{NO}_{2}$ may be counteracted by the coincident presence of NO. The results of this study clearly show that the inclusion of combustion by-products in the test atmospheres does not magnify the effect of $\mathrm{NO}_{2}$ on respiratory function.

The present study has shown that isolated hour long exposures to 0.3 and $0.6 \mathrm{ppm} \mathrm{NO}$ did not produce adverse effects in these asthmatic subjects. However, the effects of prolonged exposures to lower levels have not been examined. Two recent studies $[32,33]$ have suggested that response to allergen may be enhanced by prior exposure to $\mathrm{NO}_{2}$. Because the duration of exposures to $\mathrm{NO}_{2}$ in schools and in homes during the winter heating period is likely to be greater than the one hour exposure examined here, and because exposure is likely to occur in the presence of allergen, further studies are required to examine the effect of chronic low level exposures in domestic environments on the respiratory health of asthmatic subjects.

Acknowledgements: The authors wish to acknowledge the financial support of the National Health and Medical Research Council, the technical support of T. Trieu and L. Trevillion, the editorial and statistical advice of J. Peat and the enthusiasm of their asthmatic subjects.

\section{References}

1. Brauer M, Ryan P, Suh H, Koutrakis P, Spengler J. Measurements of nitrous acid inside two research houses. Environ Sci Technol 1990; 24: 1521-1527.

2. Ware JH, Dockery DW, Spiro A, Speizer FE, Ferris BG. Passive smoking, gas cooking and respiratory health of children living in six cities. Am Rev Respir Dis 1984; 129: 366-374.

3. Speizer FE, Ferris B, Bishop YMM, Spengler J. Respiratory disease rates and pulmonary function in children associated with $\mathrm{NO}_{2}$ exposure. Am Rev Respir Dis 1980; 121(1): 3-10.

4. Hasselblad V, Humble CG, Graham MG, Anderson HS. Indoor environmental determinants of lung function in children. Am Rev Respir Dis 1981; 123: 479-485.

5. Melia RJW, Florey CV, Chinn S. The relation between respiratory illness in primary schoolchildren and the use of gas for cooking. I. Results from a national survey. Int J Epidemiol 1979; 8(4): 333-338.

6. Florey CV, Melia RJW, Goldstein $\mathrm{BD}$, et al. The relation between respiratory illness in primary schoolchildren and the use of gas for cooking. III. Nitrogen dioxide, respiratory illness and lung infection. Int $J$ Epidemiol 1979; 8(4): 347-353.

7. Comstock GW, Meyer MB, Helsing KJ, Tockman MS. Respiratory effects of household exposures to tobacco smoke and gas cooking. Am Rev Respir Dis 1981; 124: 143-148.

8. Morrow PE, Utell MJ. Responses of susceptible subpopulations to nitrogen dioxide. Cambridge, MA, Health Effects Institute, 1989; Research Report No. 23.

9. Orehek J, Massari J, Gayrard P, Grimaud C, Charpin J. Effects of short-term, low-level nitrogen dioxide exposure on bronchial sensitivity of asthmatic patients. J Clin Invest 1976; 57: 301-307.

10. Linn W, Solomon J, Trim S, et al. Effects of exposure to $4 \mathrm{ppm}$ nitrogen dioxide in healthy and asthmatic subjects. Arch Environ Health 1985; 40: 234-239.

11. Burdon JGW, Killian KJ, Stubbing DG, Campbell EJM. Effect of background loads on the perception of added loads to breathing. J Appl Physiol: Respirat Environ Exercise Physiol 1983; 54(5): 1222-1228.

12. Gregg I, Nunn AJ. Peak expiratory flow in normal subjects. BMJ 1973; 3: 282.

13. Godfrey S, Camburoff PL, Nairn JR. Spirometry, lung volumes and airway resistance in normal children aged 5-18 yrs. Br J Dis Chest 1970; 64: 15-24.

14. Morris J, Koski A, Johnson L. Spirometric standards for healthy nonsmoking adults. Am Rev Respir Dis 1971; 103: 57-67.

15. Polgar G, Promadhat V. Pulmonary function testing in children: techniques and standards. Philadelphia, Saunders, 1971.

16. Yan K, Salome C, Woolcock A. Rapid method for the 
measurement of bronchial responsiveness. Thorax 1983; 38: 760-765.

17. Reddel HK, Salome CM, Woolcock AJ, Peat JK. Which index of peak expiratory flow is most useful in the management of stable asthma? Am J Respir Crit Care Med 1995; 151: 1320-1325.

18. Salome CM, Peat JK, Britton WJ, Woolcock AJ. Bronchial responsiveness in two populations of Australian schoolchildren. I. Relation to respiratory symptoms and diagnosed asthma. Clin Allergy 1987; 17: 271-281.

19. Woolcock AJ, Peat JK, Salome CM, et al. Prevalence of bronchial hyperresponsiveness and asthma in a rural adult community. Thorax 1987; 42: 361-368.

20. Mohsenin V. Airway responses to nitrogen dioxide in asthmatic subjects. J Toxicol Environ Health 1987; 22(4): 371-380.

21. Jorres R, Magnussen H. Effect of $0.25 \mathrm{ppm}$ nitrogen dioxide on the airway response to methacholine in asymptomatic asthmatic patients. Lung 1991; 169(2): 77-85.

22. Bylin G, Lindvall T, Rehn T, Sundin B. Effects of shortterm exposure to ambient nitrogen dioxide concentrations on human bronchial reactivity and lung function. Eur J Respir Dis 1985; 66(3): 205-217.

23. Bylin G, Hedenstierna G, Lindvall T, Sundin B. Ambient nitrogen dioxide concentrations increase bronchial responsiveness in subjects with mild asthma. Eur Respir $J$ 1988; 1(7): 606-612.

24. Kleinman MT, Bailey RM, Linn WS, et al. Effects of $0.2 \mathrm{ppm}$ nitrogen dioxide on pulmonary function and response to bronchoprovocation in asthmatics. J Toxicol Environ Health 1983; 12(4-6): 815-826.

25. Hazucha MJ, Ginsberg JF, McDonnell WF, et al. Effects of $0.1 \mathrm{ppm}$ nitrogen dioxide on airways of normal and asthmatic subjects. J Appl Physiol:Respirat Environ Exercise Physiol 1983; 54(3): 730-739.

26. Rubinstein I, Bigby Bg, Reiss TF, Boushey HAJ. Shortterm exposure to $0.3 \mathrm{ppm}$ nitrogen dioxide does not potentiate airway responsiveness to sulfur dioxide in asthmatic patients. Am Rev Respir Dis 1990; 141(2): 381-385.

27. Folinsbee LJ. Does nitrogen dioxide exposure increase airways responsiveness? Toxicol Ind Health 1992; 8(5): 273-283.

28. Koenig JQ, Covert DS, Marshall SG, Van Belle G, Pierson WE. The effects of ozone and nitrogen dioxide on pulmonary function in healthy and in asthmatic adolescents. Am Rev Respir Dis 1987; 136: 1152-1157.

29. Bauer MA, Utell MJ, Morrow PE, Speers DM, Gibb FR. Inhalation of $0.03 \mathrm{ppm}$ nitrogen dioxide potentiates exercise-induced bronchospasm in asthmatics. Am Rev Respir Dis 1986; 134: 1203-1208.

30. Linn WS, Shamoo DA, Avol EL, et al. Dose-response study of asthmatic volunteers exposed to nitrogen dioxide during intermittent exercise. Arch Environ Health 1986; 41(5): 292-296.

31. Hogman M, Frostell CG, Hedenstrom H, Hedenstierna G. Inhalation of nitric oxide modulates adult human bronchial tone. Am Rev Respir Dis 1993; 148: 14741478 .

32. Tunnicliffe WS, Burge PS, Ayres JG. Effect of domestic concentrations of nitrogen dioxide on airway respones to inhaled allergen in asthmatic patients. Lancet 1994; 344: 1733-1736.

33. Devalia JL, Rusznak C, Herdman MJ, Trigg CJ, Tarraf H, Davies RJ. Effect of nitrogen dioxide and sulphur dioxide on airway response of mild asthmatic patients to allergen inhalation. Lancet 1994; 344: 1668-1671. 